\title{
EXPERIMENTAL ANALYSIS AND MODELLING OF GRINDING AISI D3 STEEL
}

\author{
P V Vinay ${ }^{1 *}$ and Ch Srinivasa Rao $^{2}$ \\ 1* Department of Mechanical Engineering, School of Engineering, GVP College for \\ Degree and PG Courses(Technical Campus), Rushikonda, Visakhapatnam, INDIA. \\ ${ }^{2}$ Department of Mechanical Engineering, Andhra University College of Engineering, \\ Andhra University, Visakhapatnam, INDIA.
}

\begin{abstract}
Grinding of hardened steels for the realisation of better surface quality of the workpiece is an essentiality of high productivity environments. The surface grinding of high carbon high chromium steels like AISI D3 with a production level grinding wheel used in the industry is the driver of the present research article. The experimentation is done in dry as well as pool cooling conditions to ascertain the better of the two conditions in providing a better set of cutting forces and surface finish. A mathematical model for evaluating the forces generated during grinding is evolved and on comparison of the results obtained from the model with the ones from experimentation is found to be correlating. The usage of production level vitrified grinding wheel has shown good results in terms of lower forces generated and good surface finish during surface grinding. The results are optimised and the set of inputs which yield good surface finish and low forces are given. Dry grinding of AISI D13 yields good surface finish than wet grinding. Surface finish of 0.14 microns is achievable using dry grinding.
\end{abstract}

\section{KEYWORDS}

Hardened Steel; Surface Grinding; Cutting forces; Surface finish; Tool Steel

\section{INTRODUCTION}

Grinding is a complex abrasive cutting process where machining happens with geometrically unspecified cutting edges[1]. Grinding interface involves material removal by contact, between the grinding wheel and a random structured surface of the work piece. Surface quality is the main criterion in surface grinding and is influenced by various parameters like workpiece parameters, wheel parameters and process parameters[2]. Out of the aforementioned parameters to achieve better surface finish process parameters like wheel speed, depth of cut, table speed and dressing condition can be determined by a set of experiments. RSM can conveniently optimise the process parameters by using a lesser number of experimental runs.

Dhavlikar et al.[3]presented the Taguchi and response method to determine the robust condition for minimization of out of roundness error of workpieces for the centerless grinding process. Shaji and Radhakrishnan[2]elaborated the use of simultaneous optimisation of multiple quality characteristics which is the need in case of machining. Taguchi method considers the optimization of a single parameter at a time. Alauddin et.al.[4]have used RSM to predict tool life in end milling process. The optimum cutting conditions were determined for a required tool life by a second-order prediction model. Suresh et al.[5]used RSM and genetic algorithm(GA) for predicting the surface roughness and optimizing process parameters while machining mild steel using CNMG tools on a lathe.Koshy etal.[6]tested face milling of AISID2 at 58HRC with cBN 
tools and found acceptable tool life together with excellent surface finish in the range of 0.1 to 0.2 $\mu \mathrm{m}$ in Ra. However, the tools failed by fracture of the cutting edge and the authors compared the results with AISI H13 steel at a hardness of $52 \mathrm{HRC}$ and detailed PCBN tool performance on the workpieces with a $40 \mathrm{~cm}^{3}$ material removal. Braghini and Coelho[7]tested cBN tools to face mill AISI D6 steel at 58HRC, removing $15 \mathrm{~cm}^{3}$ of material with $300 \mu \mathrm{m}$ of tool wear. Surface finish(Ra) was observed to be 0.2 and $0.3 \mu \mathrm{m}$. Nevertheless, graphs reveal scattered points that prevent strong conclusions to be made about surface quality and productivity. Vila et al.[17] worked on given an economical solution for machining flat surfaces and concluded that face milling with chamfered edge preparation in coated tungsten carbide tools is better than surface grinding in terms of product quality and economics.M jafar Hadad and M Hadi, 2013[21] stressed on the need to use MQL in grinding but found that the effect of MQL on grinding is minimal and suggested the usage of vegetable oil as coolant to have a good surface finish when compared to ester mixed coolant.

A wide range of tool steels are employed to produce machined moulds and dies [8-11]. In forging and die casting, the choice is generally hot work tool steels (AISI Group Hseries) which can withstand the relatively high working temperatures involved, typically $315-650^{\circ} \mathrm{C}$. These include chromium-based (e.g. AISI H13) and tungsten-based (e.g.AISI H21) compositions. Some alloy steels are also utilised. Forging dies are mainly employed at a hardness of 45-56HRC, while plastics moulds for thermoplastics and thermosets are typically made from cold work tool steels including AISI P20, AISI P6, AISI O1 (oil hardening) and AISI S7(shock resisting). Tool steels conforming to AISI Group Dare widely used in the manufacture of blanking and coldformingdies and in-service hardness for such steels is in the range 58-62 HRC [6].

The aspect of surface grinding of high carbon high chromium steels (AISI D3) that are used in various applications with a requirement of good surface finish in dies and moulds with production level grinding wheels used by the industry is the driver in selecting the material and wheel combination. The realisation of good surface finish with a grinding wheel mostly used in the industry for higher material removal and surface finish is the research interest of the present paper. The grinding wheel (32A46-54J8VBE) mentioned, is a combinational wheel used in the industry for enhancing the material removal rate as well as realisation of good surface finish possesses an equal(50-50) weight percentage mix of 46 and 54 grit size grains. The selection of the grinding wheel is done according to the economic and availability criterion[1, 12, 15].

AISI D3 steel is used in manufacturing slitting cutters, plug gauges, lathe centers, drawing dies for bars and wire, burnishing rolls, bending, forming and seaming rolls, blanking, cold forming, stamping and lamination dies being some of the applications. Manufacture of dies and moulds with a good tolerance and better surface finish are chosen as the application requirement for the selection of the material with low wear, high hardness and heat resistivity. The use of experimentation for determining the factors that influence the process of grinding has been the usual practice in the industry. Instead of performing the experimentation the utilisation of physical models for evaluating the influencing factors is helpful for the industry personnel in guiding them to select the type of equipment for the process to be performed. This has propelled research $[1,17,20,22,23]$ in the direction of modelling of forces and surface roughness being the primary outputs to be optimised for enhancement of productivity. Modelling of forces generated during grinding without performing experimentation is one of the primary concerns addressed and compared with experimentation by the present work.

\section{Mathematical Modelling OF ForCes}

Grinding is characterised by multiple cutting edges with large negative rake angles with small volume of chip removal. The cutting grain shape as given byM.C. Shaw[12] is taken as spherical 
and the depth of engagement with respect to the grit diameter is very small. Fig. 1 illustrates how the interaction of a grain in a grinding wheel with the workpiece will be, irrespective of the type of grinding process (cylindrical or surface). The grain area in contact with the workpiece can be approximated to the shape of a circular grain being cut off by a chord. The maximum distance of the chord or the depth of cut(d) from the outer surface of the grain which indents the workpiece is the maximum chip thickness that can be attained during grinding.

Area A shown in fig. 1 can be found out from[24] as

$$
A=1 / 2 r_{g}^{2} *(\theta-\sin \theta)
$$

Substituting area A as given by equation (1), $\theta$ as the angle subtended and length of chord as

$$
b=r_{g} \sin \theta / 2
$$

into indentation force $(F)$ to be acting on the grain, the following equations for normal $\left(f_{n i}\right)$ and tangential $\left(f_{\mathrm{t}}\right)$ forces coming on to each grit can be formulated as

$$
\begin{aligned}
& f_{n i}=\frac{3 \pi}{8 d} * r_{g}{ }^{3} * H *\left[\frac{\sin \theta}{2}(\theta-\sin \theta)-\mu * \sin ^{2}\left(\frac{\theta}{2}\right)(\theta-\sin \theta)\right] \\
& f_{t i}=\frac{3 \pi}{8 d} * r_{g}{ }^{3} * H *\left[\sin ^{2}\left(\frac{\theta}{2}\right)(\theta-\sin \theta)+\mu * \frac{\sin \theta}{2}(\theta-\sin \theta)\right]
\end{aligned}
$$

The value of coefficient of friction becomes significant when the depth of cut is less than 0.05 times the average diameter of the grains in the grinding wheel [25]. Thus by neglecting the frictional effect the force equations 3 and 4 transform into

$$
\begin{aligned}
f_{n i} & =\frac{3 \pi}{96 d} * r_{g}{ }^{3} * H * \theta^{4} \\
f_{t i} & =\frac{3 \pi}{96 d} * r_{g}{ }^{3} * H * \theta^{4} *[\sin (\theta / 2) / \cos (\theta / 2)]
\end{aligned}
$$

As given by [23].

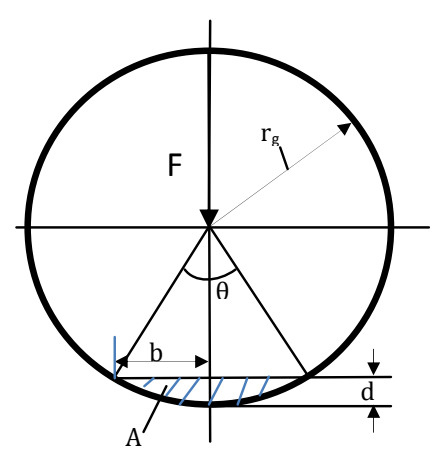

Figure 1. Grain approximation Chen and Rowe (1996)[22], Spiegel(1999)[24].

These above said relations can be solved by knowing the type of grain used in the grinding wheel, that will yield the grain radius value $\left(\mathrm{r}_{\mathrm{g}}\right)$, the used depth of cut(d) and the hardness $(\mathrm{H})$ of the workpiece material being the inputs to the equations the forces being generated during the process. These relations from the industrial point-of-view are user friendly when assessing the probable forces attained during grinding with a specific wheel and workpiece combination. 


\section{EXPERIMENTAL SETUP}

The experiments are carried out on a Craftsman SG 3060 "Precicraft" horizontal surface grinding machine with a horizontal spindle(with a 5HP motor) and having a hydraulic motor to run the worktable. The machine has a magnetic chuck on which a Kistler 9257B, a 3-component quartz dynamometer is loaded with a vice to hold the workpiece as shown in Fig. 2, is used to find the forces being generated during machining and the signal is amplified by a charge amplifier(Kistler $5070 \mathrm{~A})$ and are recorded online. The grinding wheel used is of 350x50x127 (DxWxH) size and is having the specification of $32 \mathrm{~A} 46-54 \mathrm{~J} 8 \mathrm{VBE}$ which is a production level grinding wheel as shown in Fig. 3. This type of wheel is used for enhancing the material removal rate and to obtain a good surface quality. Mineral oil as coolant mixed in the ratio of 1:20 for cooling and lubrication of the ground surface is used in the wet condition.

AISI D3 tool steel is chosen as the workpiece and is hardened to $60 \mathrm{HRC}$ by oil quenching from $980^{\circ} \mathrm{C}$ and tempered at $200^{\circ} \mathrm{C}$. It is machined engaging the full grinding wheel width and taking five passes. Table 1 shows the chemical composition of AISI D3 workpiece used in the experimentation.

Table 1. Chemical composition(weight \%) of AISI D3 steel.

\begin{tabular}{|c|c|c|c|c|c|c|c|c|c|c|c|}
\hline $\mathbf{C}$ & $\mathbf{S i}$ & $\mathbf{M n}$ & $\mathbf{P}$ & $\mathbf{S}$ & $\mathbf{C r}$ & $\mathbf{N i}$ & $\mathbf{M o}$ & $\mathbf{A l}$ & $\mathbf{C u}$ & $\mathbf{Z n}$ & $\mathbf{F e}$ \\
\hline 2.06 & 0.55 & 0.449 & 0.036 & 0.056 & 11.09 & 0.277 & 0.207 & 0.0034 & 0.13 & 0.27 & 85 \\
\hline
\end{tabular}

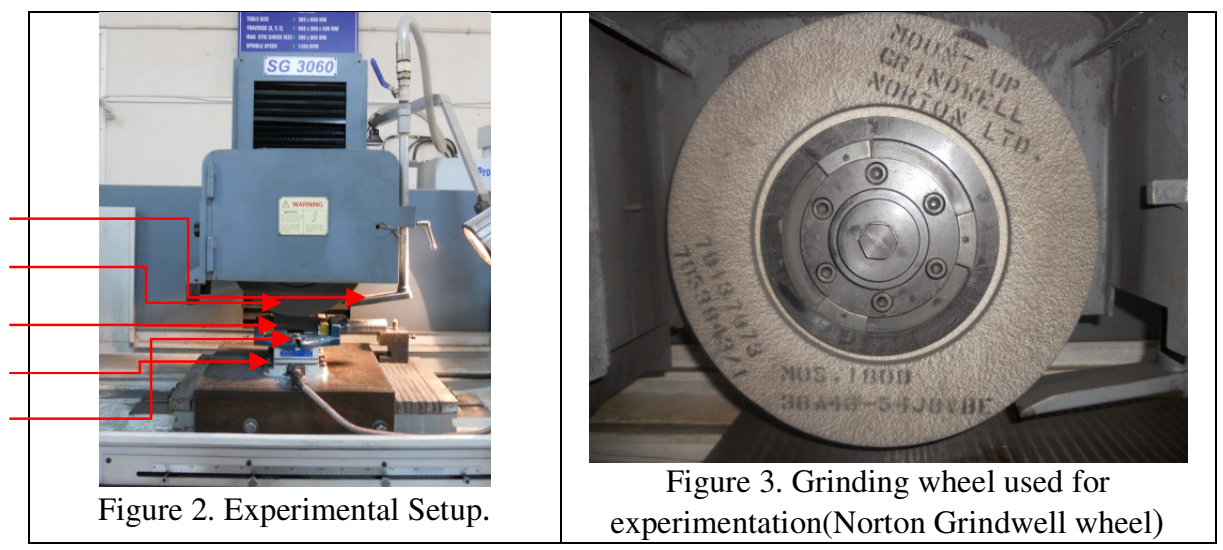

Response Surface Methodology(RSM) is used to optimize the number of experiments. The process parameters selected to be analysed are feed, depth of cut and dressing depth with the rpm of the wheel held constant at 1450. The experiments are carried out in dry as well as wet environments by varying the parameters according to the number of experiments generated in RSM based CCD(Central Composite Design)using Minitab 16.The experiments are conducted as per design matrix generated for three levels and three parameters as shown in Table 2. The dressing of the wheel is done using a diamond dresser at the set depth for two passes with one spark out.

The outputs measured online during the experimentation are the forces and surface roughness. Forces are found using Kistler 9257B piezoelectric dynamometer during machining for five passes where the workpiece is engaged by the full grinding wheel width. After each experiment, the surface finish of the ground part is measured using a Mitutoyo Surftest SJ210 as shown in Fig. 4.Three readings are taken to confirm the roughness. Confirmatory tests are carried out to verify the force values obtained during grinding. 


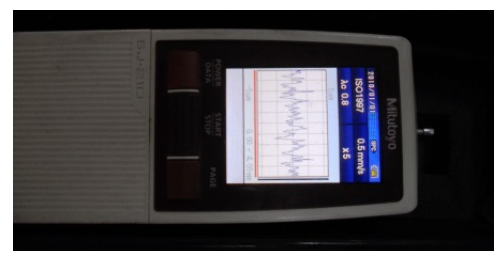

Figure 4.Mitutoyo Surftest SJ210

Table 2. Factors and levels chosen for grinding process

\begin{tabular}{|l|c|c|c|}
\hline \multirow{2}{*}{\multicolumn{1}{|c|}{ Factors }} & \multicolumn{3}{|c|}{ Levels } \\
\cline { 2 - 4 } & $\mathbf{- 1}$ & $\mathbf{0}$ & $\mathbf{1}$ \\
\hline Feed speed $(\mathrm{m} / \mathrm{min})$ & 5 & 15 & 25 \\
\hline Depth of Cut $(\mathrm{mm})$ & 0.008 & 0.014 & 0.02 \\
\hline Dressing Depth $(\mathrm{mm})$ & 0.008 & 0.014 & 0.02 \\
\hline
\end{tabular}

The levels for the factors are chosen after conducting trial experiments. The depth of cut and dressing depth are limited to 20 microns, beyond which the wheel showed a tendency of higher wear and possible breakage. The feed rate is chosen in equal intervals upto $25 \mathrm{~m} / \mathrm{min}$ which is the maximum that can be attained by the machine.

\section{RESULTS AND DISCUSSION}

The focus of the present study is to evaluate the relative effect of the selected factors/parameters on the forces generated and the surface finish obtained during grinding of AISI D3 steel using a production level grinding wheel. Two modes of grinding(dry and wet) are performed and evaluated to assess the better of the two with the environmental impact in mind. The experimental results obtained are compared with the values computed from the model and equations governing the forces and surface roughness in grinding the workpiece are developed.

\subsection{Dry Grinding}

Dry grinding is performed on the workpiece(AISI D3 steel) to analyse the forces generated and the surface finish attained using the production level grinding wheel. The regression analysis of the data generated from experimentation yielded the equations for tangential force, normal force and surface roughness as

$$
\begin{aligned}
& F_{x}=38.054+ 8.451 \times \text { Feed }+1.712 \times \text { Depth of cut }+2.862 \times \text { Dressing depth }+7.137 \\
& \times(\text { Depth of cut })^{2}-8.623 \times(\text { Dressing depth })^{2}
\end{aligned}
$$


International Journal of Recent advances in Mechanical Engineering (IJMECH) Vol.4, No.1, February 2015

Table 3.ANOVA table for tangential force data in dry grinding.

\begin{tabular}{|l|l|l|l|l|l|l|l|}
\hline \multicolumn{1}{|c|}{ Source } & DF & Seq SS & Adj SS & \multicolumn{1}{|c|}{ Adj MS } & $\begin{array}{c}\text { F- } \\
\text { Value }\end{array}$ & \multicolumn{1}{|c|}{ P } & \multicolumn{1}{|c|}{ Remarks } \\
\hline Regression & 9 & 1225.27 & 1225.27 & 136.141 & 8.36 & 0.001 & Significant \\
\hline Feed(m/min) & 1 & 714.19 & 714.19 & 714.194 & 43.87 & 0 & Significant \\
\hline Depth of Cut(mm) & 1 & 29.31 & 29.31 & 29.309 & 1.8 & 0.209 & Insignificant \\
\hline Dressing Depth(mm) & 1 & 81.91 & 81.91 & 81.91 & 5.03 & 0.049 & Significant \\
\hline Feed(m/min)*Feed(m/min) & 1 & 54.45 & 15.95 & 15.948 & 0.98 & 0.346 & Insignificant \\
\hline $\begin{array}{l}\text { Depth of Cut(mm)*Depth of } \\
\text { Cut(mm) }\end{array}$ & 1 & 48.75 & 140.07 & 140.069 & 8.6 & 0.015 & Significant \\
\hline $\begin{array}{l}\text { Dressing } \\
\text { Depth(mm)*Dressing } \\
\text { Depth(mm) }\end{array}$ & 1 & 204.49 & 204.49 & 204.488 & 12.56 & 0.005 & Significant \\
\hline $\begin{array}{l}\text { Feed(m/min)*Depth of } \\
\text { Cut(mm) }\end{array}$ & 1 & 15.4 & 15.4 & 15.401 & 0.95 & 0.354 & Insignificant \\
\hline $\begin{array}{l}\text { Feed(m/min)*Dressing } \\
\text { Depth(mm) }\end{array}$ & 1 & 41.31 & 41.31 & 41.314 & 2.54 & 0.142 & Insignificant \\
\hline $\begin{array}{l}\text { Depth of Cut(mm)*Dressing } \\
\text { Depth(mm) }\end{array}$ & 1 & 35.45 & 35.45 & 35.448 & 2.18 & 0.171 & Insignificant \\
\hline Residual Error & 10 & 162.78 & 162.78 & 16.278 & & & \\
\hline Total & 19 & 1388.05 & & & & & \\
\hline
\end{tabular}

Normal force equation developed for dry grinding is

$$
\begin{aligned}
& F_{z}=205.323+ 3.78 \times \text { Feed }+32.53 \times \text { Depth of cut }+5.1 \times \text { Dressing depth }-61.83 \\
& \times(\text { Feed })^{2}+31.32 \times(\text { Depth of cut })^{2}
\end{aligned}
$$

Table 4. ANOVA table for normal force during dry grinding

\begin{tabular}{|l|l|l|l|l|l|l|l|}
\hline \multicolumn{1}{|c|}{ Source } & \multicolumn{1}{c|}{ DF } & \multicolumn{1}{c|}{ Seq SS } & \multicolumn{1}{c|}{ Adj SS } & \multicolumn{1}{c|}{ Adj MS } & \multicolumn{1}{c|}{ F } & \multicolumn{1}{c|}{ P } & Remarks \\
\hline Regression & 9 & 31394.3 & 31394.3 & 3488.3 & 7.89 & 0.002 & Significant \\
\hline Feed(m/min) & 1 & 142.6 & 142.6 & 142.6 & 0.32 & 0.583 & Insignificant \\
\hline Depth of Cut(mm) & 1 & 10584.6 & 10584.6 & 10584.6 & 23.94 & 0.001 & Significant \\
\hline Dressing Depth(mm) & 1 & 259.5 & 259.5 & 259.5 & 0.59 & 0.461 & Insignificant \\
\hline Feed(m/min)*Feed(m/min) & 1 & 13537.7 & 10514.3 & 10514.3 & 23.78 & 0.001 & Significant \\
\hline $\begin{array}{l}\text { Depth of Cut(mm)*Depth of } \\
\text { Cut(mm) }\end{array}$ & 1 & 2113.2 & 2697 & 2697 & 6.1 & 0.033 & Significant \\
\hline $\begin{array}{l}\text { Dressing Depth(mm)*Dessing } \\
\text { Depth(mm) }\end{array}$ & 1 & 617.4 & 617.4 & 617.4 & 1.4 & 0.265 & Insignificant \\
\hline Feed(m/min)*Depth of Cut(mm) & 1 & 1541.2 & 1541.2 & 1541.2 & 3.49 & 0.091 & Insignificant \\
\hline Feed(m/min)*Dressing Depth(mm) & 1 & 1813.2 & 1813.2 & 1813.2 & 4.1 & 0.07 & Insignificant \\
\hline $\begin{array}{l}\text { Depth of Cut(mm)*Dressing } \\
\text { Depth(mm) }\end{array}$ & 1 & 784.9 & 784.9 & 784.9 & 1.78 & 0.212 & Insignificant \\
\hline Residual Error & 10 & 4420.7 & 4420.7 & 442.1 & & & \\
\hline Total & 19 & 35814.9 & & & & & \\
\hline
\end{tabular}

Surface roughness equation developed for dry grinding is given below

$$
\begin{aligned}
R_{a}=0.3642+ & 0.047 \times \text { Feed }+0.027 \times \text { Depth of cut }+0.023 \times \text { Dressing depth }-0.089 \\
& \times(\text { Feed })^{2}-0.079 \times(\text { Depth of cut })^{2}+0.092 \times(\text { Dressing depth })^{2}
\end{aligned}
$$


International Journal of Recent advances in Mechanical Engineering (IJMECH) Vol.4, No.1, February 2015

Table 5. ANOVA table for surface roughness generated during surface grinding in dry mode

\begin{tabular}{|l|l|l|l|l|l|l|l|}
\hline \multicolumn{1}{|c|}{ Source } & DF & \multicolumn{1}{c|}{ Seq SS } & \multicolumn{1}{c|}{ Adj SS } & Adj MS & F & P & Remarks \\
\hline Regression & 9 & 0.105826 & 0.105826 & 0.011758 & 4.83 & 0.011 & Significant \\
\hline Feed(m/min) & 1 & 0.022468 & 0.022468 & 0.022468 & 9.22 & 0.013 & Significant \\
\hline Depth of Cut(mm) & 1 & 0.007728 & 0.007728 & 0.007728 & 3.17 & 0.105 & Insignificant \\
\hline Dressing Depth(mm) & 1 & 0.00557 & 0.00557 & 0.00557 & 2.29 & 0.161 & Insignificant \\
\hline Feed(m/min)*Feed(m/min) & 1 & 0.034031 & 0.022208 & 0.022208 & 9.12 & 0.013 & Significant \\
\hline $\begin{array}{l}\text { Depth of Cut(mm)*Depth of } \\
\text { Cut(mm) }\end{array}$ & 1 & 0.00657 & 0.01754 & 0.01754 & 7.2 & 0.023 & Significant \\
\hline $\begin{array}{l}\text { Dressing Depth(mm)*Dressing } \\
\text { Depth(mm) }\end{array}$ & 1 & 0.023345 & 0.023345 & 0.023345 & 9.59 & 0.011 & Significant \\
\hline Feed(m/min)*Depth of Cut(mm) & 1 & 0.000325 & 0.000325 & 0.000325 & 0.13 & 0.722 & Insignificant \\
\hline Feed(m/min)*Dressing Depth(mm) & 1 & 0.00316 & 0.00316 & 0.00316 & 1.3 & 0.281 & Insignificant \\
\hline $\begin{array}{l}\text { Depth of Cut(mm)*Dressing } \\
\text { Depth(mm) }\end{array}$ & 1 & 0.002628 & 0.002628 & 0.002628 & 1.08 & 0.323 & Insignificant \\
\hline Residual Error & 10 & 0.024355 & 0.024355 & 0.002436 & & & \\
\hline Total & 19 & 0.130181 & & & & & \\
\hline
\end{tabular}

\subsubsection{Surface Plots}

Surface plots show the optimal response points obtained with different process parameters.
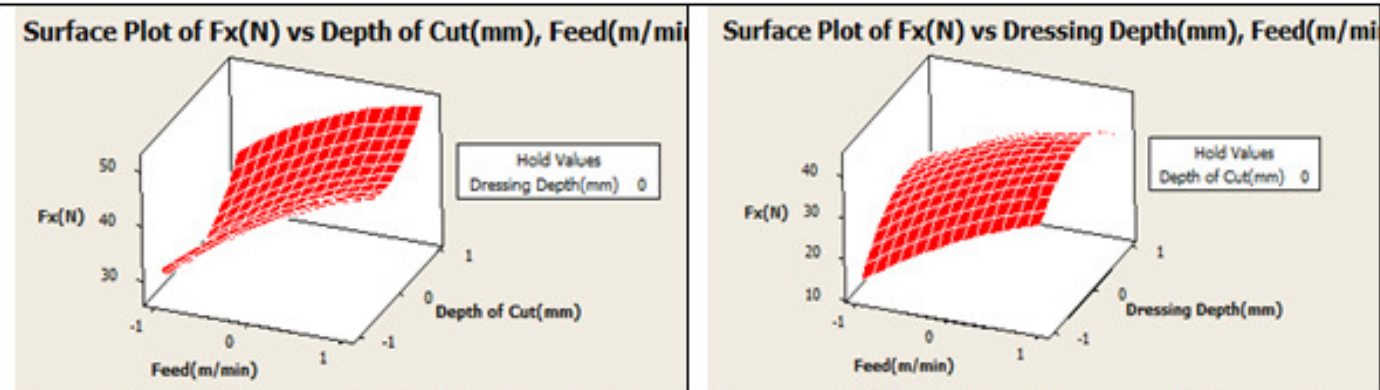

Surface Plot of Fx(N) vs Dressing Depth(mm), Depth of Cut(m

Figure 5. Surface plots of tangential force during

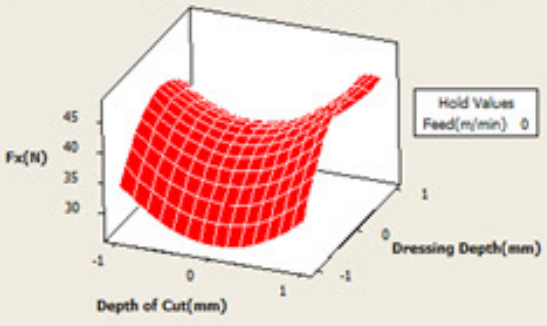

dry grinding with various parameters. 


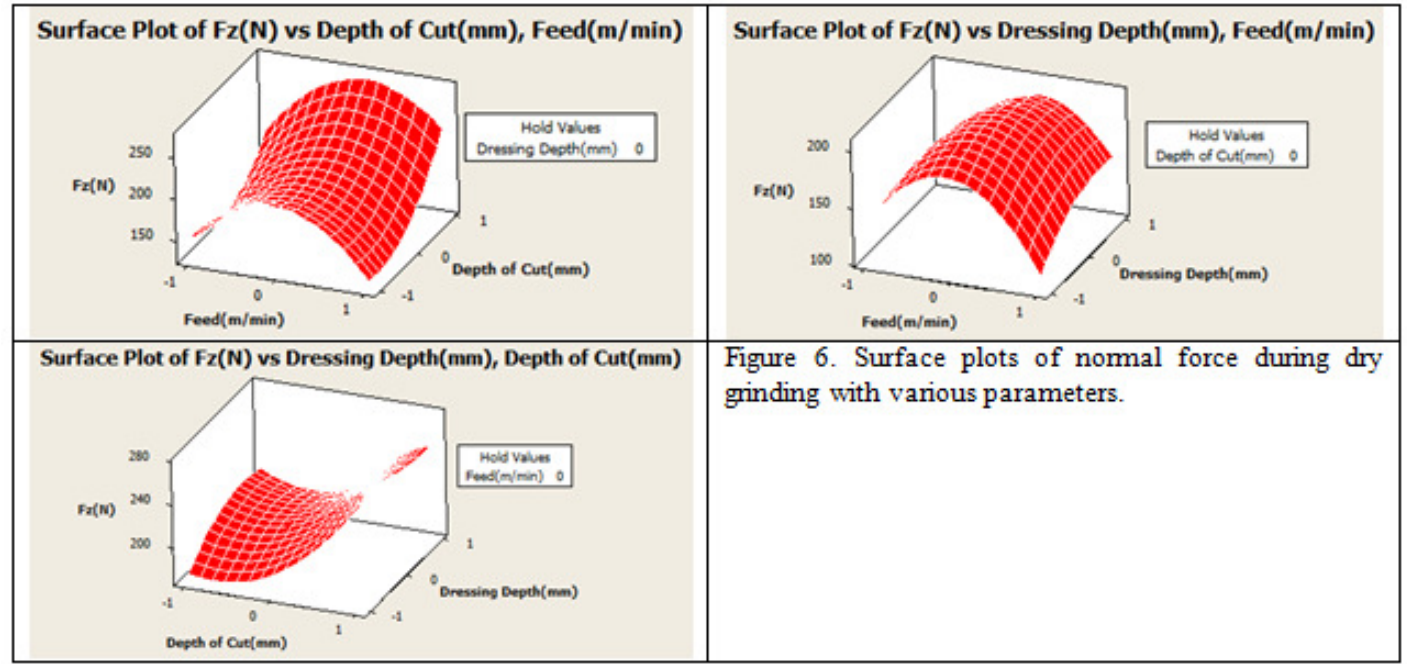

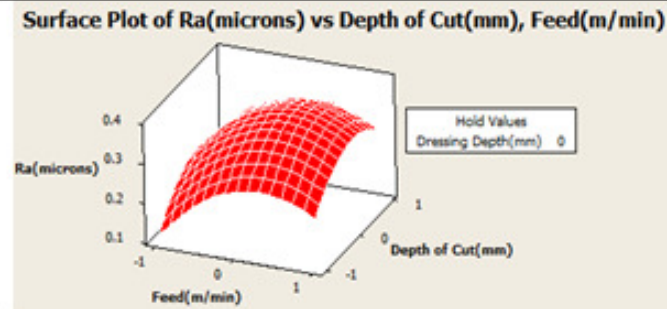

Surface Plot of Ra(microns) vs Dressing Depth(mm), Depth of Cut(mm)

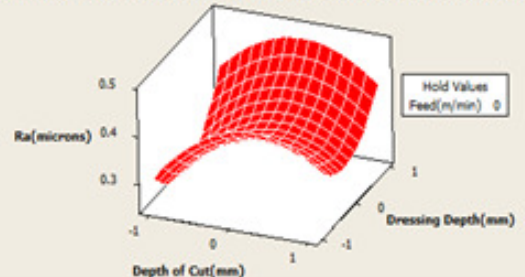

Surface Plot of Ra(microns) vs Dressing Depth(mm), Feed(m/min)

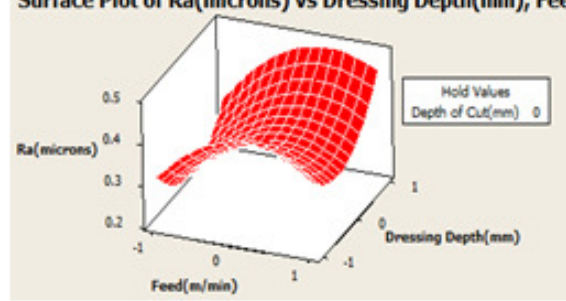

Figure 7. Surface plots of Surface roughness during dry grinding with various parameters

The increase in tangential force value with an increase in feed rate and depth of cut is attributed to the enhancement of material removal rate. The dressing depth is found to be less influencing than feed rate and depth of cut. The normal force is seen as being influenced by feed rate and depth of cut more and the higher feed rate of $25 \mathrm{~m} / \mathrm{min}$ and lower depth of cut of 8 microns as can be seen from Fig. 6 are found to be showing minimal normal force. Even with depth of cut enhancement to the 14 micron level the variation in the normal force being exerted on the workpiece is found to have minimal variation as the grains of the wheel attain the cutting capability. Further enhancement in the depth of cut shows an increase in the normal force this is due to the increase in the amount of material being cut.

Surface roughness plots gives an interesting observation where in with an increase in feed rate, the roughness value goes up and at higher feed rate the value of roughness comes down and the same happens with an increase in depth of cut this phenomenon is because of the smaller grains of the wheel attain cutting capability, with it the surface roughness is also improved. This decrease in roughness is not evident in wheels using single grit grains. The dressing depth has an inverse of the trend discussed prior as the dressing depth is at 20 microns the smaller grains also break and create more marks on the surface with it the roughness is enhanced. The 14 micron 
International Journal of Recent advances in Mechanical Engineering (IJMECH) Vol.4, No.1, February 2015

dressing depth shows promising results where the roughness obtained is better than other two dressing depths as the smaller sized grains present in the wheel also participate in the cutting.

\subsection{Wet Grinding}

Wet grinding is performed on the workpiece(AISI D3 steel) to study the forces and the surface finish achieved using the production level grinding wheel when a coolant is applied. The regression analysis of the data generated from experimentation yielded the following equations for tangential force, normal force and surface roughness.

$$
\begin{gathered}
F_{x}=40.91+7.94 * \text { feed }+1.431 * \text { DOC }+3.03 * \text { dress depth }-13.05 *(\text { dress depth })^{2} \\
+6.57 * \text { feed } * \text { DOC }
\end{gathered}
$$

Table 6. ANOVA table for tangential force data acquired during wet grinding.

\begin{tabular}{|l|l|l|l|l|l|l|l|}
\hline \multicolumn{1}{|c|}{ Source } & DF & Seq SS & \multicolumn{1}{|c|}{ Adj SS } & Adj MS & \multicolumn{1}{c|}{ F } & \multicolumn{1}{c|}{ P } & \multicolumn{1}{c|}{ Remarks } \\
\hline Regression & 9 & 1883.94 & 1883.94 & 209.327 & 6.83 & 0.003 & Significant \\
\hline Feed(m/min) & 1 & 631.39 & 631.39 & 631.389 & 20.59 & 0.001 & Significant \\
\hline Depth of Cut(mm) & 1 & 20.48 & 20.48 & 20.478 & 0.67 & 0.433 & Insignificant \\
\hline Dressing Depth(mm) & 1 & 92.17 & 92.17 & 92.173 & 3.01 & 0.114 & Insignificant \\
\hline Feed(m/min)*Feed(m/min) & 1 & 132.46 & 37.37 & 37.371 & 1.22 & 0.296 & Insignificant \\
\hline $\begin{array}{l}\text { Depth of Cut(mm)*Depth of } \\
\text { Cut(mm) }\end{array}$ & 1 & 137.87 & 7.66 & 7.657 & 0.25 & 0.628 & Insignificant \\
\hline $\begin{array}{l}\text { Dressing Depth(mm)*Dressing } \\
\text { Depth(mm) }\end{array}$ & 1 & 468.59 & 468.59 & 468.593 & 15.28 & 0.003 & Significant \\
\hline Feed(m/min)*Depth of Cut(mm) & 1 & 345.58 & 345.58 & 345.582 & 11.27 & 0.007 & Significant \\
\hline Feed(m/min)*Dressing Depth(mm) & 1 & 55.23 & 55.23 & 55.23 & 1.8 & 0.209 & Insignificant \\
\hline $\begin{array}{l}\text { Depth of Cut(mm)*Dressing } \\
\text { Depth(mm) }\end{array}$ & 1 & 0.17 & 0.17 & 0.174 & 0.01 & 0.941 & Insignificant \\
\hline Residual Error & 10 & 306.7 & 306.7 & 30.67 & & & \\
\hline Total & 19 & 2190.64 & & & & & \\
\hline
\end{tabular}

Normal force equation developed for surface grinding in wet condition is given below

$$
\begin{aligned}
& F_{z}=357.53+ 14.48 \times \text { feed }+74.42 \times \text { depth of cut }+14.86 \times \text { dressing depth }-71.95 \\
& \times(\text { depth of cut })^{2}-74.05 \times(\text { dressing depth })^{2}
\end{aligned}
$$

Table 7. ANOVA table for normal force data acquired during wet grinding

\begin{tabular}{|l|l|l|l|l|l|l|l|}
\hline \multicolumn{1}{|c|}{ Source } & DF & Seq SS & Adj SS & \multicolumn{1}{c|}{ AdjMS } & \multicolumn{1}{c|}{ F } & \multicolumn{1}{c|}{ P } & \multicolumn{1}{c|}{ Remarks } \\
\hline Regression & 9 & 143613 & 143613 & 15957 & 7.65 & 0.002 & Significant \\
\hline Feed(m/min) & 1 & 2097 & 2097 & 2096.7 & 1 & 0.34 & Insignificant \\
\hline Depth of Cut(mm) & 1 & 55383 & 55383 & 55383.4 & 26.54 & 0 & Significant \\
\hline Dressing Depth(mm) & 1 & 2208 & 2208 & 2208.2 & 1.06 & 0.328 & Insignificant \\
\hline Feed(m/min)*Feed(m/min) & 1 & 27863 & 461 & 461.2 & 0.22 & 0.648 & Insignificant \\
\hline Depth of Cut(mm)*Depth of Cut(mm) & 1 & 31820 & 14236 & 14236.2 & 6.82 & 0.026 & Significant \\
\hline $\begin{array}{l}\text { Dressing Depth(mm)*Dressing } \\
\text { Depth(mm) }\end{array}$ & 1 & 15079 & 15079 & 15079.4 & 7.23 & 0.023 & Significant \\
\hline Feed(m/min)*Depth of Cut(mm) & 1 & 4109 & 4109 & 4108.7 & 1.97 & 0.191 & Insignificant \\
\hline Feed(m/min)*Dressing Depth(mm) & 1 & 5015 & 5015 & 5015 & 2.4 & 0.152 & Insignificant \\
\hline Depth of Cut(mm)*Dressing Depth(mm) & 1 & 38 & 38 & 38.3 & 0.02 & 0.895 & Insignificant \\
\hline Residual Error & 10 & 20868 & 20868 & 2086.8 & & & \\
\hline Total & 19 & 164481 & & & & & \\
\hline
\end{tabular}


International Journal of Recent advances in Mechanical Engineering (IJMECH) Vol.4, No.1, February 2015

Surface roughness obtained by experimentation on AISI D3 tool steel is formulated by the following equation and the table 8 shows the ANOVA table with the significant and insignificant variables.

$$
\begin{aligned}
R_{a}=0.641+ & 0.06 \times \text { feed }-0.042 \times \text { depth of cut }+0.002 \times \text { dress depth } \\
& -0.11(\text { depth of cut })^{2}+0.09 \times \text { feed } \times \text { depth of cut }-0.06 \times \text { feed } \\
& \times \text { dress depth }+0.05 \times \text { depth of cut } \times \text { dress depth }
\end{aligned}
$$

Table 8 - ANOVA table for surface roughness during wet grinding of the workpiece

\begin{tabular}{|l|l|l|l|l|l|l|l|}
\hline \multicolumn{1}{|c|}{ Source } & DF & \multicolumn{1}{c|}{ SeqSS } & \multicolumn{1}{c|}{ AdjSS } & \multicolumn{1}{c|}{ AdjMS } & \multicolumn{1}{c|}{ F } & \multicolumn{1}{c|}{ P } & \multicolumn{1}{c|}{ Remarks } \\
\hline Regression & 9 & 0.215201 & 0.215201 & 0.023911 & 7.18 & 0.002 & Significant \\
\hline Feed(m/min) & 1 & 0.036361 & 0.036361 & 0.036361 & 10.92 & 0.008 & Significant \\
\hline Depth of Cut(mm) & 1 & 0.018404 & 0.018404 & 0.018404 & 5.53 & 0.041 & Significant \\
\hline Dressing Depth(mm) & 1 & 0.000053 & 0.000053 & 0.000053 & 0.02 & 0.902 & Insignificant \\
\hline Feed(m/min)*Feed(m/min) & 1 & 0.001186 & 0.005063 & 0.005063 & 1.52 & 0.246 & Insignificant \\
\hline $\begin{array}{l}\text { Depth of Cut(mm)*Depth of } \\
\text { Cut(mm) }\end{array}$ & 1 & 0.038019 & 0.037062 & 0.037062 & 11.13 & 0.008 & Significant \\
\hline $\begin{array}{l}\text { Dressing Depth(mm)*Dressing } \\
\text { Depth(mm) }\end{array}$ & 1 & 0.000983 & 0.000983 & 0.000983 & 0.3 & 0.599 & Insignificant \\
\hline Feed(m/min)*Depth of Cut(mm) & 1 & 0.066795 & 0.066795 & 0.066795 & 20.07 & 0.001 & Significant \\
\hline Feed(m/min)*Dressing Depth(mm) & 1 & 0.032896 & 0.032896 & 0.032896 & 9.88 & 0.01 & Significant \\
\hline $\begin{array}{l}\text { Depth of Cut(mm) } \text { Dressing } \\
\text { Depth(mm) }\end{array}$ & 1 & 0.020503 & 0.020503 & 0.020503 & 6.16 & 0.032 & Significant \\
\hline Residual Error & 10 & 0.033286 & 0.033286 & 0.003329 & 1.71 & 0.285 & Insignificant \\
\hline Total & 19 & 0.248487 & & & & & \\
\hline
\end{tabular}

\subsubsection{Surface Plots}

The surface plots obtained during wet grinding are given below. They illustrate the various variations of tangential, normal forces and surface roughness with the variations in process parameters.

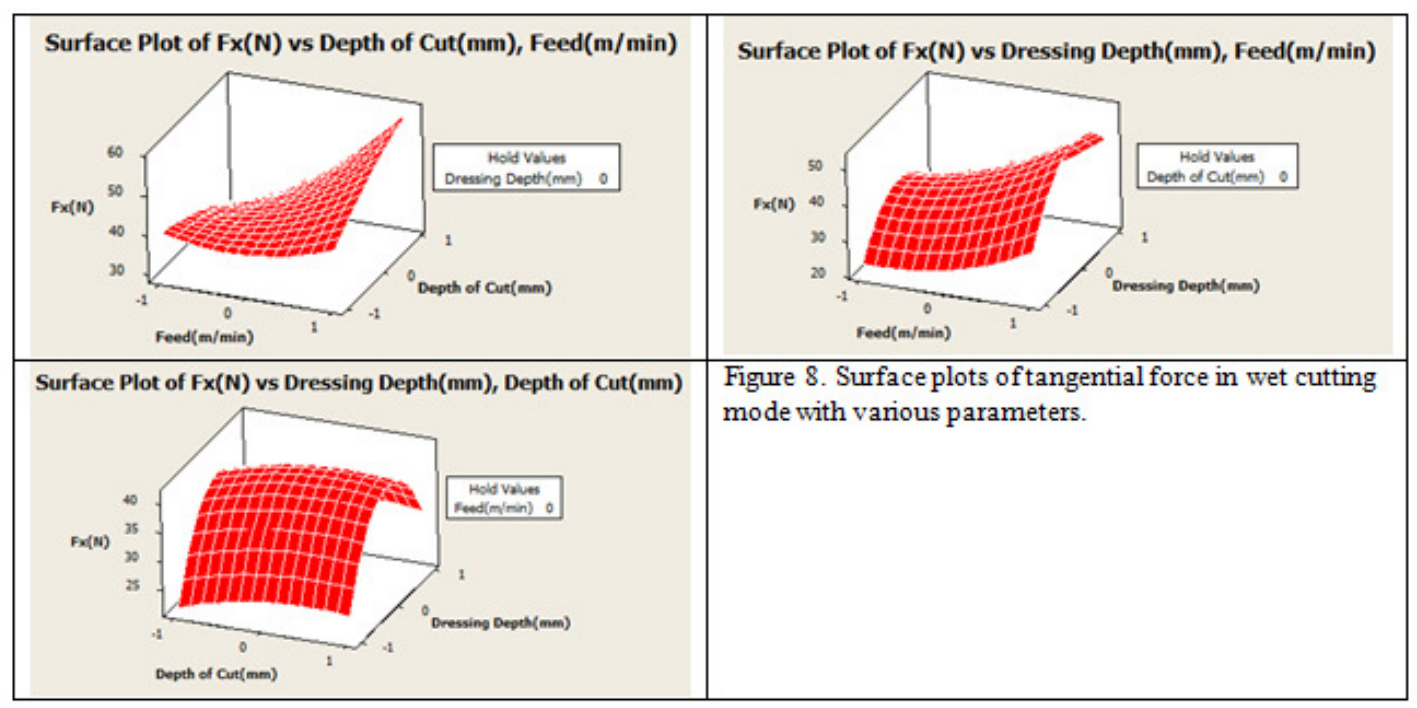




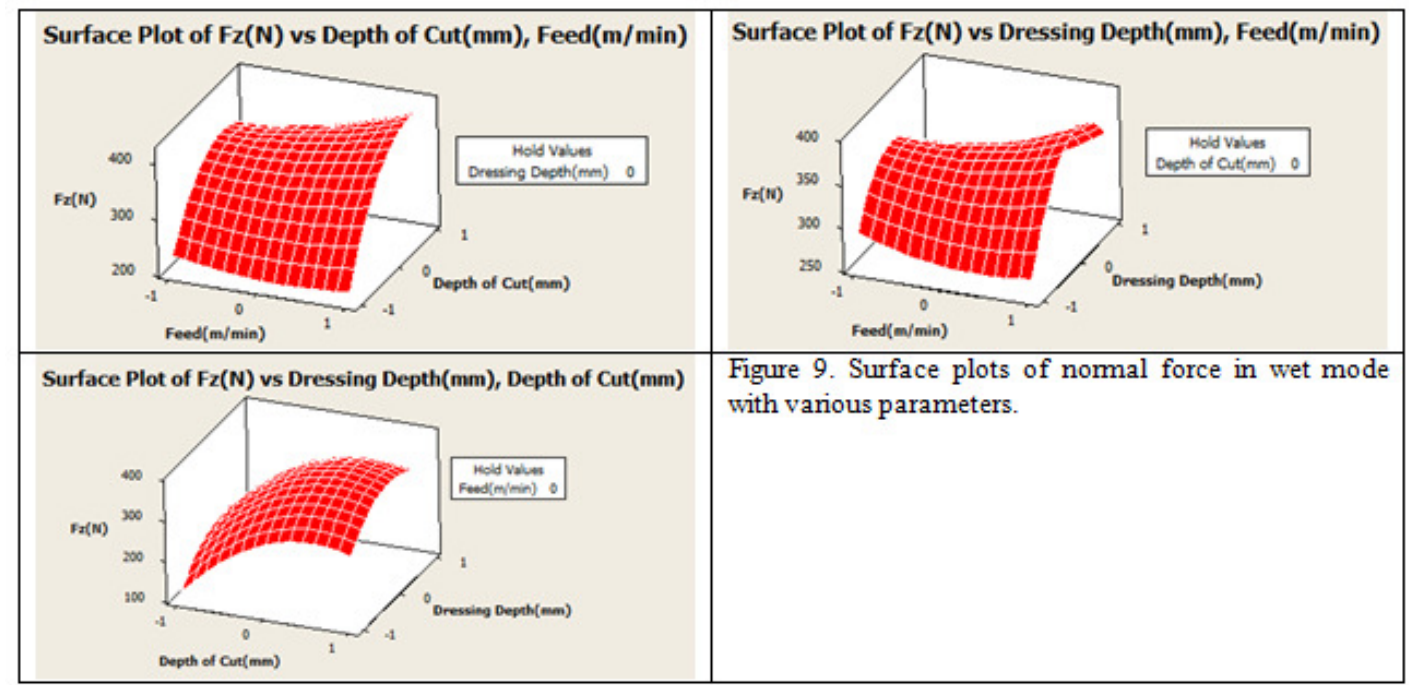

The tangential force and normal force generated during surface grinding in wet condition shows a considerable change when depth of cut and dressing depth is enhanced. The forces show less variation when feed rate is changed from low to high.

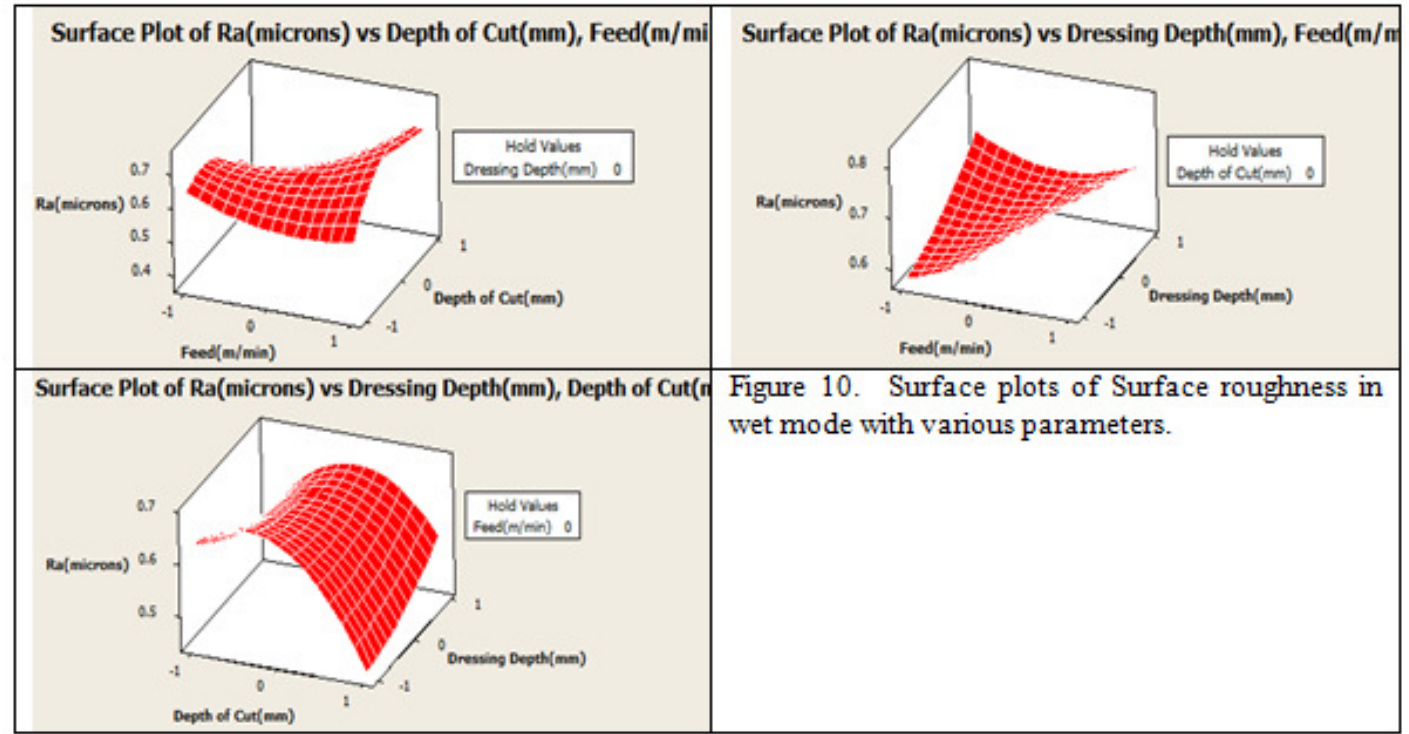

The lower values of forces observed in the figures shown above are due to the fact that the wheel is a combinational wheel and the cutting capability is observed to be enhanced as the depth of cut is increased due to the increase in the number of cutting edges being exposed to the workpiece.

Finer dressing depth of 8 microns produces denser cutting edges on the grains; these edges are not sufficient to penetrate into the work material causing high normal forces and hence rubbing and ploughing components will be higher at this dressing depth. As a result of high friction and increased amount of plastic deformation the tangential force is also higher[1,12]. With coarse dressing depth of 20 microns the grits are damaged severely and the wheel has good number of cutting edges to penetrate the workpiece giving lower force components [13,14].

The higher normal force component at mediocre(14 microns) dressing depth is due to loading of the wheel and the fact that the finer grains are damaged very lightly and expose bigger grain 
lands. The decline in the force components at higher dress depth of 20 microns is due to the fact that the smaller grains are broken, and large numbers of edges are available to cut the workpiece.

The enhancement in surface roughness at higher dressing depths in the wet condition is due to the presence of coolant and the effective disposal of chips and heat with lower amount of breakage of grits. At finer dressing depth the bigger grains are not effected exposing bigger grain lands and the finer grains which have cutting capability perform majority of material removal hence the tangential and the normal forces recorded are lower. The enhancement in the dressing depth allows the lower sized grains also be exposed more and the bigger grains are ruptured reducing the grain lands and hence the forces generated are enhanced at mediocre dressing depths. Further increase in the dressing depth to 20 microns, will expose more of the smaller grains and hence the forces(tangential and normal) are brought down. This scenario of reduction of forces at higher dressing depths is not found when single grit wheels used in grinding.

The surface finish obtained is dependent on the depth of cut as well as dressing depth whose enhancement shows a decrement in the roughness which is also the case in wet grinding where the finish tends to proceed improve as depth of cut and dressing depth increase.

Surface roughness is reduced with an increase in depth of cut as the smaller size grains come into action and improve the surface finish.

The equations modelled yield the values of forces generated during grinding, and the values obtained during grinding of AISI D3 steel correlate with the ones obtained from modelling. This shows that the modelling can be utilised for finding the forces generated during surface grinding of tool steels.

\section{OPTIMISATION}

The response optimisation of the responses evaluated for the chosen set of parameters gives the following graphs for dry and wet grinding.

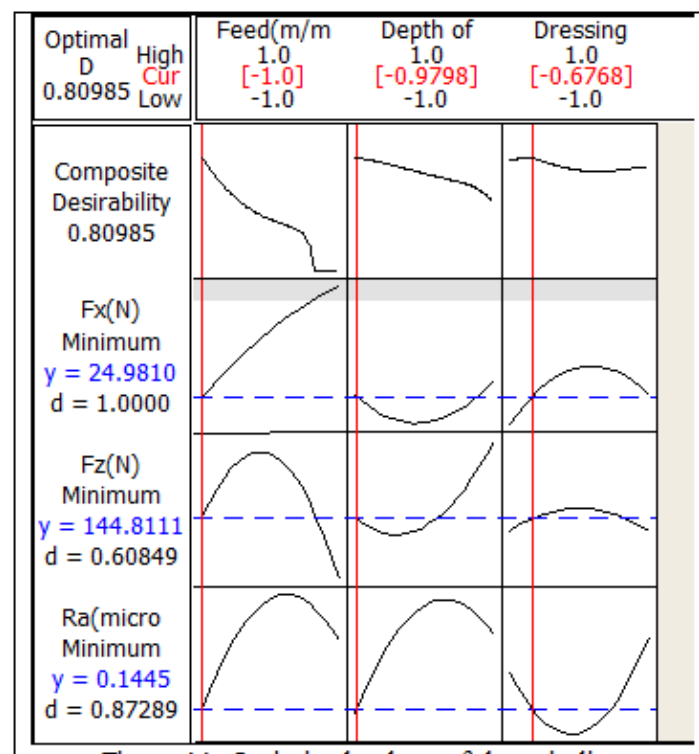

Figure 11. Optimised values of dry grinding

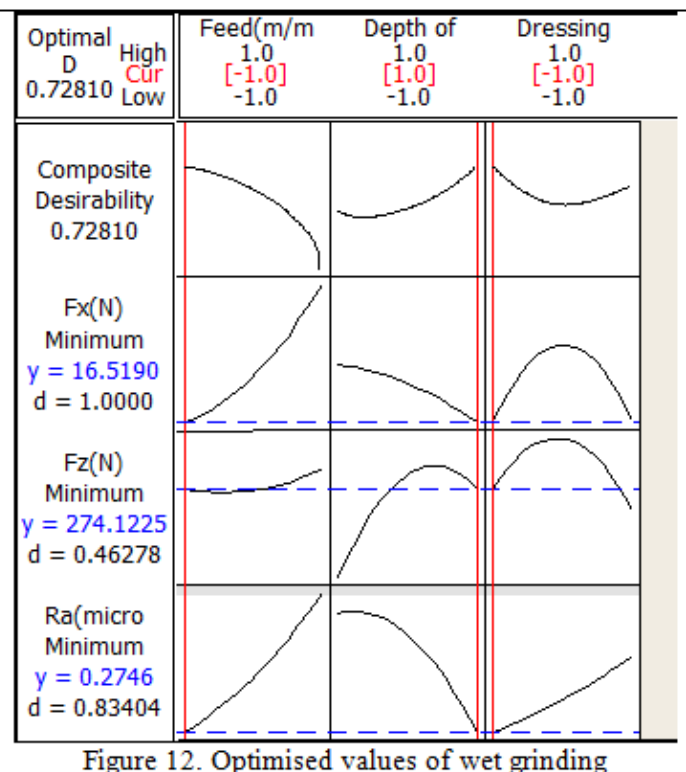

Figure 12. Optimised values of wet grinding

The optimised values of tangential, normal forces and surface roughness when all the responses are minimised simultaneously are found to be at low feed, low depth of cut and low dressing 
depth for dry grinding. The optimal response for wet grinding is obtained at low feed, high depth of cut and low dressing depth. The desirability of the functions for dry and wet grinding are at $80 \%$ and $72 \%$ respectively.

\section{Conclusions}

The present study analyses the effect of various process parameters on the quality of the workpiece obtained by grinding using a production type grinding wheel. RSM has been applied to find out the relative effect of parameters like feed, depth of cut and dressing depth on surface roughness and the forces generated by their relative changes. The results obtained during machining in dry and wet conditions have been compared with the modelling and discussed.

The tangential forces generated during grinding are less than the ones expected with single grit sized wheels. The tangential forces generated are not higher than $45 \mathrm{~N}$ recorded during grinding with a production typegrinding wheel, this is way low than the forces that might be generated when a single grit wheel is used. The forces will affect the power consumption to grind.

The usage of production typegrinding wheel is suggested to achieve good surface roughness in tune with the one required by the die and mould industry (about 2 microns) and also the forces generated are lesser which are suggestive of lesser surface damage. The cost of the combinational wheel is less when compared to the conventional wheel of a smaller grit size. The comparison of smaller grit is done keeping in mind the surface roughness factor but the tangential force generated by the smaller grit sized wheel will be more when compared to the combinational(production) wheel.

The surface finish obtained in the dry grinding of AISI D3 is better when compared to that of wet grinding. The normal forces generated when coolant is used are high when compared to that of the dry grinding mode. Dry grinding of tool steel of this variety is suggested using production type grinding wheel.

The production type grinding wheel can be used to grind AISI D3 workpiece having hardness of HRC 60 for achieving surface roughness ranging from 0.14 to 0.45 in dry grinding and 0.26 to 0.8 in wet grinding using a coolant having a concentration of 1:20 mineral oil to water.

The best surface finish is obtained at low feed, high depth of cut and low dressing depth in wet and at low feed, low depth of cut and low dressing depth in dry condition. The least normal force is found at high feed, low depth of cut and low dress depth. The least tangential force is at low feed, high depth of cut and low dressing depth.

The surface finish is good when having high depth of cut and high dressing depth using the production type grinding wheels which will not be the case with conventional grinding wheels. The process parameters are optimised to yield the right cutting parameters and are correlated by conducting the experiments at the above said values.

\section{REFERENCES}

[1] Malkin, S. (1989) Grinding Technology theory and applications of machining with abrasives, Society of manufacturing engineers: Dearborn, Michigan.

[2] S. Shaji \& V. Radhakrishnan. (2003) "Analysis of process parameters in surface grinding with graphite as lubricant based on the Taguchi method", Journal of Materials Processing Technology,Vol. 141 (1), pp 51-59. 
[3] M.N. Dhavlikar; M.S. Kulkarni; V. Mariappan.(2003) "Combined Taguchi and dual response method for optimization of a centerless grinding operation", Journal of Materials Processing Technology, 132 (1-3); 90-94.

[4] M. Alauddin, M.A.; El Baradie; M.S.J. Hashmi.(1997) "Prediction of tool life $\mathrm{n}$ end milling by response surface methodology", Journal of Materials Processing Technology,Vol. 71 (3);456-465.

[5] P.V.S. Suresh; P.V.V. Rao; S.G. Deshmukh.(2002) "A genetic algorithmic approach for optimization of surface roughness prediction model", International Journal of Machine Tools and Manufacture, Vol. 42 (6); 675-680.

[6] Koshy, P; Dewes, R.C; Aspinwall, D.K.(2002) "High speed end milling of hardened AISI D2 tool steel (similar to 58 HRC). Journal of Materials Processing Technology,Vol. 127; 266-273.

[7] Braghini, A.; Coelho, R.T.(2001) "An investigation of the wear mechanisms of polycrystalline cubic boron nitride (PCBN) tools when end milling hardened steels at low/medium cutting speeds", International Journal of Advanced Manufacturing Technology, Vol. 17; 244-251.

[8] Selection of materials for molds for plastics and rubbers, (1980) ASM Metals Handbook, Properties and Selection: Stainless Steels, Tool Materials and Special-Purpose Metals, Vol. 3, 9th ed., ASM International, pp. 546-550.

[9] Dies and die materials for hot forging, (1988) ASM Metals Handbook -Forming and Forging, ASM International, Vol. 14, 9th ed., pp. 43-58.

[10] Machining of tool steels, (1989) ASM Metals Handbook-Machining, vol. 16, 9th ed., ASM International, pp. 708-732.

[11] Worldwide equivalent iron and steels, (1993) Materials Data Series, 3rd ed., ASM International, ISBN 0871704544.

[12] M.C. Shaw. (1996) Principles of Abrasive Processing, Oxford University Press, New York.

[13] C.P. Bateja; E.J. Pattinson;A.W.J. Chisholm.(1972) "The influence of dressing on the performance of grinding wheels". Annals of CIRP,Vol. 21 (1),pp 81-82.

[14] J. Verkerk; A.J. Pekelhering. (1979) "The influence of dressing operation on productivity in precision in grinding", Annals of CIRP,Vol. 28 (2),pp 487-495.

[15] M.J. Jackson; B. Mills. (2000) "Materials selection applied to vitrified alumina \& cBN grinding wheels", Journal of Materials Processing Technology,Vol. 108,pp 114-124.

[16] K. Chakraborty; A.B. Chattopadhyay; A.K. Chakrabarti.(2003) "A study on the grindability of niobium microalloyed forging quality HSLA steels” Journal of Materials Processing Technology,Vol. 141, pp 404-410.

[17] C. Vila, H.R.Siller, C.A.Rodriguez, G.M.Bruscas, J.Serrano.(2012) "Economical and technological study of surface grinding versus face milling in hardened AISI D3 steel machining operations", International journal of Production Economics,Vol. 138, pp 273-283.

[18] Ioan D. Marinescu; Mike Hitchiner; Eckart Uhlmann; W. Brian Rowe; Ichiro Inasaki. (2007) Handbook of Machining with Grinding Wheels, CRC Press, New York.

[19] Iqbal, A.; He, N.; Li, L.; Zha, W.W.; Xia, Y. (2006) "Influence of tooling parameters in high-speed milling of hardened steels”, Key Engineering Materials,Vol. 315-316,pp 676-680.

[20] Siller, H.R.; Vila, C.; Rodriguez, C.A.; Abellan, J.V. (2009) "Study of face milling of hardened AISI D3 steel with a special design of carbide tools", International Journal of Advanced Manufacturing Technology,Vol. 40, pp 12-25.

[21] Mohammadjafar Hadad, Mostafa Hadi. (2013) “An investigation on surface grinding of hardened stainless steel S34700 and aluminum alloy AA6061 using minimum quantity of lubrication (MQL) technique", International Journal of Advanced Manufacturing Technology, Vol. 68(9-12),pp 21452158.

[22] Xun Chen, W B Rowe. (1996) "Analysis and Simulation of the Grinding Process PART II: Mechanics of Grinding”, International Journal of Machine Tools and Manufacture,Vol. 36(8), pp 883896.

[23] P.V. Vinay, Ch. Srinivasa Rao, I.H. Nagaraja Rao. (2014) "Novel Force Modelling Technique for Grinding", Journal of Manufacturing Science and Production,Vol. 14(3), pp 177-182.

[24] MR Spiegel. (1999) Mathematical Handbook of Formulas and Tables, New York, McGraw Hill.

[25] Korolev AV, Novoselov Yu K. (1989) "Probabilistic Analysis of Abrasive Machining. Interaction of the Tool and the Blank in Abrasive Machining”, Saratov: Izd. Sarat. Univ. Vol. 2. 